\title{
The Effects of Isokinetic Exercise on Knee Joint Combined Russian Current Stimulation
}

\author{
Dong-Hoon Kim', Ho-Bal Jung² \\ 'Department of Physical Therapy, Graduate School of Hanseo University, Seosan; ${ }^{2}$ Department of Physical Therapy, Ansan University, Ansan, Korea
}

Purpose: This study was conducted to determine how stimulation using Russian current changes isokinetic exercise performance of quadriceps muscle and its antagonist muscles.

Methods: Subjects were 20 20-year-old healthy adults who were instructed in the flexion to extension of knees in angular velocity $60^{\circ} /$ sec and $180^{\circ} / \mathrm{sec}$ using a Biodex (Biodex system 3 ). We measured the difference in muscle performance between the Russian current stimulated at the same time during the flexion to extension of knees and not stimulated.

Results: The results showed that when Russian current stimulation was applied at the angular velocity $60^{\circ} / \mathrm{sec}$, the flexed and extended muscles and the angular velocity $180^{\circ} / \mathrm{sec}$ increased significantly, but the peak torque of flexing muscles at the angular velocity $180^{\circ} / \mathrm{sec}$ did not increase.

Conclusion: These findings suggest that Russian current stimulation with isokinetic exercise of the knee joint could affect the quadriceps muscle and its antagonist muscle performance of muscle strength and endurance.

Keywords: Electric stimulation, Muscle contraction, Muscle strength, Endurance

\section{서 론}

재활이란 장애를 가진 사람이 신체장애를 극복하여 최적의 상태로 되돌리는 과정을 말한다. 손상이나 질병이 발생되면 근력이 저하되 기 때문에 손상이나 질병에서 회복될 때는 각 개인의 정상적인 근력 을 되찾는 것이 필수적이고 ${ }^{2,3}$ 근력강화를 위한 다양한 재활 프로그 램이 활용되고 있다. ${ }^{4}$

근력은 근육에 부과된 요구에 대해 장력과 힘을 생산하는 수축성 능력을 말하며, 저항이 주어진 상황에서 최대로 수축하는 동안 근육 이 이를 극복하여 발휘할 수 있는 최대의 힘이라 할 수 있으며 근지구 력(muscle endurance)은 장시간 동안 근육이 최대 하에서 힘을 발휘 하는 능력으로 근력 발휘를 지속적으로 유지하는 능력을 말한다.5, 이러한 근력(Muscle strength)은 생체 역학적인 면에서 신체 기능을 평 가할 수 있는 기준의 하나로 사용되고, 외력을 받았을 때 그 부위를 보호하고 일상생활을 가능하게 하는 근원이 된다?

골격근의 기능을 증진시키는 재활방법에는 전기 자극에 의한 수
축을 이용하는 방법과 수의적 수축을 이용하는 방법이 있으며, 전기 자극에 의한 근 수축은 수의적 등척성 운동에 의한 근 수축과 유사 하게 근력 향상을 가져온다고 하였다. ${ }^{8}$ 따라서 건강한 사람이나 근 소 모 또는 근 위축이 있는 사람의 골격근 힘을 향상시키기 위한 물리치 료 분야에서 전기 자극이 사용된다.9

골격근의 근력 강화에 효과적인 전기 자극 방법 10 중 $50 \%$ 순환 주기 (duty cycle)와 $50 \mathrm{~Hz}$ 돌발 변조 주파수(burst modulation)를 발생시킬 수 있는 $2,500 \mathrm{~Hz}$ 교류인 러시안 전류(Russian current)" ${ }^{11}$ 는 환자보다는 건강인 및 운동선수에게 근력증강을 목적으로 하는 자극에 많이 사 용되며, 일반적으로 적용되는 전기자극의 유형에 비해 더 큰 근육의 토크(torque)와 편안함을 유발할 수 있는 특징을 가지고 있다.12

1976년 몬트리올 올림픽에서 구소련 운동선수에게 근력증가 목적 으로 러시안 전류를 적용한 이래로 ${ }^{11} \mathrm{Lee}$ 등 ${ }^{13}$ 은 정상인을 대상으로 러시안 전류자극을 통해 최대 토크(peak torque) 값이 증가하여 근력 증가에 효과가 있다고 보고하였고, Jung과 Bang ${ }^{14}$ 은 하지골절 후 회복 기 환자를 대상으로 한 연구에서 러시안 전류가 넙다리네갈래근육 
의 근 수행능력에 효과적이었으며 하지근육의 근력 강화를 위해 효 과적인 치료방법이라 언급하였다. 이렇듯 러시안 전류는 운동선수뿐 만 아니라 환자 및 정상인의 근력 향상의 목적으로 활용되고 있다.

골격근의 근력 강화의 수의적 수축방법 중 하나로 등속성 장비 (Biodex)를 활용한 등속성 운동방법 또한 근력 증진을 위한 효과적인 운동방법으로 제시되고 있다. ${ }^{15}$ 등속성 장비(Biodex)를 이용한 등속 성 운동은 하지의 근력에 있어 등장성 운동과 유사한 운동효과가 있 으며, ${ }^{16}$ 저속 각속도로 운동시 위팔두갈래근의 최대 근력 향상에 효 과적이라 보고되고 있다. ${ }^{7}$ 또한 요통환자의 근 기능 개선에도 등속 성 운동프로그램이 활용되고 있다.18 이렇듯 등속성 장비는 선수, 환 자 및 일반인의 근력향상 및 재활을 목적으로 하는 대표적인 장비이 다. 또한 등속성 장비는 근 기능의 기계적 운동평가에 대한 높은 신 뢰도를 보이고 있어19,20 정상인과 환자의 근력 및 균형평가에도 활용 되고 있다.21-23

등속성 장비를 활용한 재활방법은 기존의 등장성이나 등척성 운 동보다 관절의 회전 기능 향상에 보다 큰 효과가 있어 선행연구에서 보듯이 많은 운동과의 비교연구가 이루어져 왔으나 수의적인 등척성 운동에 의한 근 수축과 유사한 근력향상을 가져오는 러시안 전류를 병합한 등속성 운동방법과의 비교 연구는 아직 미비한 실정이다.

따라서 본 연구는 근력향상에 검증된 등속성 장비의 7 개 주요관 절(어깨관절, 팔꿉관절, 손목관절, 엉덩관절, 무릎관절, 발목관절, 허 리부위) 측정 부위 중 빼, 관절 및 연골장애를 가장 많이 호발하는 무 릎관절을 대상으로 하여 러시안 전류 자극을 병합한 등속성 운동의 효과를 다양한 인체관절의 운동평가에 높은 신뢰도를 보이는 등속 성 장비를 통해 검증하여, 운동선수, 환자 및 정상인의 다양한 관절 의 재활 및 근력향상 프로그램을 위한 이론적 근거를 제시하고자 한 다. ${ }^{24,25}$

\section{연구방법}

\section{1. 연구대상}

본 연구는 2014년 8월 11 일부터 14일까지 자발적 참여의사를 밝힌 20 명을 대상으로 하였다.

연구 이전에 무릎관절의 수술 병력이 없고 운동 제한이 없는 신체 건강한 참여자를 모집하여 전기자극에 민감한 반응을 보인 경우는 연구 대상에서 제외하였다. 대상군은 남자 5 명, 여자 15 명으로 평균

Table 1. General characteristics of the subjects

\begin{tabular}{llccc}
\hline Group & Gender N & Age (year) & Height $(\mathrm{cm})$ & Weight $(\mathrm{kg})$ \\
\hline Experimental & Male 5 & $22.1 \pm 2.2$ & $164.6 \pm 7.3$ & $55.5 \pm 6.4$ \\
Group & Female 15 & & & \\
\hline
\end{tabular}

연령은 22.1세, 키는 $164.6 \mathrm{~cm}$, 몸무게는 $55.5 \mathrm{~kg}$ 이었다(Table 1).

\section{2. 실험방법}

1) 측정도구

(1) Biodex system 3 (Biodex Medical System, USA)

본 연구에서는 짧은 시간에 효과적으로 피험자들의 근력을 평가할 수 있는 장점이 있으며 높은 신뢰도(ICC >0.90)를 가지고 있는 등속 성 근 기능 검사 장비인 Biodex system 3 (Biodex Medical System, USA) 을 이용하여 운동수행능력을 측정하였다. ${ }^{26}$

\section{2) 중재방법}

측정 전 모든 피험자에게 주동(Dominant)발을 확인한 후, 러시안 전 류 자극에 대한 두려움을 최소화하기 위하여 아래팔(Forearm) 부위 에 모의실험(simulation)을 한 후, 피험자들의 무릎관절과 근력계의 축을 일치시킨 후 벨트를 이용하여 어깨, 골반, 넙적다리 먼 부위를 고정하고 최대 폄 위치를 0 으로 하여 최대굽힘 위치까지의 관절가동 범위안에서 평가를 실시하였다.

피험자들을 수동으로 조작되는 전류 자극에 의해 근 수축을 일으 킬 때, 등속성 동작과 일치시키기 위해 2 회의 모의 동작을 연습한 후, $60 \% \mathrm{sec}$ 의 각속도와 $180 \% \mathrm{sec}$ 의 각속도에서 넙다리곧은근(Rectus Femoris)의 수축을 일으키며 통증을 느끼지 않는 범위 내의 강도와 근피 로를 적게 일으키는 맥동빈도 $30 \mathrm{bps}$, 단속시간비(on-off ratio)는 1:3으 로 설정하여 27 러시안 전류를 적용하는 경우와 적용하지 않는 두 경 우에 대하여 무릎의 굽힘(Flexion)과 폄(Extension) 동작을 4회씩 측정 하여, 최댓값과 최솟값을 제외한 데이터를 수집하였다. 검사 간 휴식 시간은 1 분으로 설정하였고, 굽힘과 폄 수축에 의한 근력검사 간의 휴식시간은 10 분으로 설정하였으며, 연습효과를 통제하기 위해 러시 안 전류를 적용하는 경우와 적용하지 않는 경우를 무작위로 선정하 여 실시하였다.

$60 \% \mathrm{sec}$ 의 각속도는 강도를 점차 증가시켜 신전하는 힘을 내기 때문 에 근력을 측정하는 데 사용하고, $180 \% / \mathrm{sec}$ 의 각속도는 일정한 속도로 강도를 유지하여 신전하는 힘을 내기 때문에 근 지구력을 측정하는 데 사용하였다.

\section{3. 분석방법}

본 연구의 자료처리는 Window SPSS 18.0 version을 통계 프로그램으 로 이용하여 모든 변수의 평균 및 표준편차를 산출하였다. 또한 러시 안 전류 자극 유무에 따른 근력 및 지구력의 근 수행능력 차이를 검 증하기 위하여 대응 표본 검정(Paired t-test)을 이용하여 분석하였으 며, 모든 통계적 유의수준은 $\mathrm{p}<0.05$ 로 하였다. 
결 과

\section{1. 무릎관절의 폄근 근력 $(60 \% \mathrm{sec})$}

각속도 $60 \% \mathrm{sec}$ 에서 무릎관절 폄의 등속성 운동수행능력 결과, 러시 안 전류를 적용하였을 경우 최대 토크는 $130.95 \pm 37.33$, 체중에 대한 최대 근력(peak tq/bw)은 $237.25 \pm 52.84$, 체중당 총 일량(total work)은 $573.87 \pm 150.54$, 평균 파워(average power)는 79.08 \pm 22.76 으로 러시안 전류를 적용하지 않았을 경우보다 모든 운동 수행능력 항목에서 유 의한 향상을 보였다 $(\mathrm{p}<0.01)$ (Table 2).

\section{2. 무릎관절의 굽힘근 근력 $(60 \% \mathrm{sec})$}

각속도 $60 \% \mathrm{sec}$ 에서 무릎관절 굽힘의 등속성 운동수행능력 결과, 러 시안 전류를 적용하였을 경우 최대 토크는 $59.68 \pm 18.98$, 체중에 대한 최대 근력은 $108.16 \pm 28.06$, 체중당 총 일량(total work)은 $309.83 \pm$ 104.10 , 평균 파워는 $40.44 \pm 15.17$ 로 러시안 전류를 적용하지 않았을 경 우보다 모든 운동 수행능력 항목에서 유의한 향상을 보였다 $(\mathrm{p}<0.01)$ (Table 2).

\section{3. 무릎관절의 폄근 지구력 $(180 \% \mathrm{sec})$}

각속도 $180 \%$ sec에서 무릎관절 폄의 등속성 운동수행능력 결과, 러시
안 전류를 적용하였을 경우 최대 토크는 $84.98 \pm 20.11$, 체중에 대한 최 대 근력은 $154.12 \pm 25.38$, 체중당 총 일량은 $795.07 \pm 200.63$, 평균 파워 는 $130.17 \pm 34.67$ 로 러시안 전류를 적용하지 않았을 경우보다 모든 운 동 수행능력 항목에서 유의한 향상을 보였다 $(\mathrm{p}<0.01)$ (Table 3$)$

\section{4. 무릎관절의 굽힘근 지구력 $(180 \% \mathrm{sec})$}

각속도 $180 \% \mathrm{sec}$ 에서 무릎관절 굽힘의 등속성 운동수행능력 결과, 러 시안 전류를 적용하였을 경우 체중에 대한 최대 근력은 $79.17 \pm 25.69$, 체중당 총 일량(total work)은 $461.31 \pm 177.81$, 평균 파워는 $69.79 \pm 28.88$ 로 유의한 향상을 보였으나 $(\mathrm{p}<0.01)$, 최대 토크는 $71.57 \pm 129.35$ 로 러 시안 전류를 적용하지 않았을 경우보다 수치는 상승하였으나 통계적 으로 유의한 향상을 보이지는 않았다( $\mathrm{p}>0.05$ ) (Table 3).

\section{고 찰}

본 연구는 재활치료 과정에서 근력 및 근지구력 향상의 효과가 보고 되고 있는 러시안 전류 자극치료를 병합한 등속성 운동의 효과를 임 상적으로 규명하고자 실시하였다.

최대 근력은 단위 체중 당 해당 근육에서 낼 수 있는 힘을 말하며 최대 힘 효율은 사용근육의 최대운동 능력을 측정하는 유용한 자료

Table 2. Muscular strength of the knee joint $\left(60^{\circ} / \mathrm{sec}\right)$

\begin{tabular}{|c|c|c|c|c|c|}
\hline & Item & Non stimulation & Stimulation & t-value & Sig. \\
\hline \multirow[t]{4}{*}{ Extension } & Peak torque & $111.70 \pm 37.60$ & $130.95 \pm 37.33$ & -6.288 & $<0.001^{*}$ \\
\hline & Peak tq/bw & $201.17 \pm 52.85$ & $237.25 \pm 52.84$ & -6.473 & $<0.001^{*}$ \\
\hline & Total work & $497.21 \pm 169.66$ & $573.87 \pm 150.54$ & -4.274 & $<0.001^{*}$ \\
\hline & Average power & $62.57 \pm 23.89$ & $79.08 \pm 22.76$ & -6.919 & $<0.001^{*}$ \\
\hline \multirow[t]{4}{*}{ Flexion } & Peak torque & $49.88 \pm 14.22$ & $59.68 \pm 18.98$ & -5.583 & $<0.001^{*}$ \\
\hline & Peak tq/bw & $90.43 \pm 19.97$ & $108.16 \pm 28.06$ & -5.630 & $<0.001^{*}$ \\
\hline & Total work & $249.49 \pm 93.97$ & $309.83 \pm 104.10$ & -3.847 & $<0.001^{*}$ \\
\hline & Average power & $29.63 \pm 12.43$ & $40.44 \pm 15.17$ & -5.850 & $<0.001^{*}$ \\
\hline
\end{tabular}

Values are mean $(\mathrm{m}) \pm$ standard deviation (SD). tq: Torque, bw: Body weight. ${ }^{*} \mathrm{p}<0.01$.

Table 3. Endurance of the knee joint $\left(180^{\circ} / \mathrm{sec}\right)$

\begin{tabular}{|c|c|c|c|c|c|}
\hline & Item & Non stimulation & Stimulation & t-value & Sig. \\
\hline \multirow[t]{4}{*}{ Extension } & Peak torque & $74.05 \pm 24.46$ & $84.98 \pm 20.11$ & -4.292 & $<0.001^{*}$ \\
\hline & Peak tq/bw & $133.63 \pm 34.38$ & $154.12 \pm 25.38$ & -4.332 & $<0.001^{*}$ \\
\hline & Total work & $697.03 \pm 261.07$ & $795.07 \pm 200.63$ & -3.499 & $0.002 *$ \\
\hline & Average power & $109.39 \pm 46.53$ & $130.17 \pm 34.67$ & -4.390 & $<0.001^{*}$ \\
\hline \multirow[t]{4}{*}{ Flexion } & Peak torque & $37.13 \pm 14.63$ & $71.57 \pm 129.35$ & -1.235 & 0.232 \\
\hline & Peak tq/bw & $66.92 \pm 21.33$ & $79.17 \pm 25.69$ & -3.434 & $0.003^{*}$ \\
\hline & Total work & $358.61 \pm 170.39$ & $461.31 \pm 177.81$ & -3.773 & 0.001 * \\
\hline & Average power & $52.68 \pm 27.95$ & $69.79 \pm 28.88$ & -3.927 & $<0.001^{*}$ \\
\hline
\end{tabular}

Values are mean $(m) \pm$ standard deviation (SD). 
로 활용되고, 체중당 총 일량은 굽힘이나 폄 중 1 회의 움직임에 있어 서 발현된 힘 효율 값의 합 중에서 최고 값을 일의 총량이라 하는데 이를 체중으로 나눈 값을 의미하며, 평균 파워는 근육이 단위시간당 할 수 있는 일의 양을 말하며 등속성 근력평가에 있어서 근 파워 측 정에 매우 유용한 지표로 활용된다. ${ }^{28-30}$

본 연구의 결과, 각속도 $60 \% \mathrm{sec}$ 에서 폄근과 굽힘근의 최대 토크, 체 중에 대한 최대 근력, 체중당 총 일량, 평균 파워에서 통계학적으로 유의한 증가를 나타내었다.

근육의 수축속도에 따라 구심성 수축과 원심성 수축은 다른 양상 을 보이게 되는데, 구심성 수축의 경우 수축속도가 감소함과 더불어 최대 근력은 점진적으로 증가하기 때문에 근력을 평가하는 데 활용 되는 각속도 $60 \% \mathrm{sec}$ 에서 모든 운동수행능력이 증가한 것으로 사료된 다. 선행 연구에서 각속도 $60 \% \mathrm{sec}$ 에서는 등척성 무릎관절의 넙다리 네갈래근의 폄힘이 최고에 도달하기 때문에 최대 토크를 측정하여 근력을 대표하는 값으로 사용한다고 하였다. ${ }^{13}$

또한 단기간의 전기 자극은 외측광근의 Type II 근섬유의 분포와, Type II 근섬유의 평균 횡단 면적을 증가하는 선행연구결과와 같이, 러시안 전류자극이 넙다리곧은근의 Type II 근섬유의 분포와 평균 횡단 면적 증가에 영향을 미치기 때문일 것으로 사료된다.32

또한 Jung ${ }^{14}$ 의 하지 골절 후 회복기 환자 20 명을 연구해서 러시안 전류가 넙다리네갈래근의 근 수행능력과 근 활성도가 증가하였다는 결과와 일치하였고, Lee 등13이 신경 전기 자극과 등척성 운동이 넙다 리네갈래근의 근력에 미치는 연구에서 각속도 $60 \% \mathrm{sec}$ 에서 최대 토크 값이 유의하게 증가하였다는 결과와도 일부 일치하였다. 하지만, 단 일 전기자극에 의한 효과를 명확히 하기에는 주기적인 근섬유의 분 포와 평균 횡단 면적 증가에 대한 분석이 이루어지지 못하여 다소 어 려움이 있다.

각속도 $180 \% \mathrm{sec}$ 에서는 굽힘근의 최대 토크를 제외한 굽힘근, 폄근의 모든 운동 수행능력 항목에서 통계학적으로 유의한 차이를 보였다.

$180 \% \mathrm{sec}$ 각속도에서 최대 토크는 단위 면적당 Type II 근섬유 구성 률과 정비례의 상관관계가 있으며, $120-300 \% \mathrm{sec}$ 각속도에서 Type II 근 섬유가 많을수록 최대 토크, 힘, 파워에서 높은 값을 나타내므로 ${ }^{33,34}$ Type II 근섬유 구성률이 높은 넙다리곧은근의 특성으로 인하여 운 동수행능력에서 유의한 향상을 보인 것으로 사료된다. 이는 무릎관 절의 등속성 신전력에 대한 상대적 등속성 굴곡력에 대한 단축성 수 축평가에서 $180 \% \mathrm{sec}$ 각속도에서 뒤넙다리근의 최대 토크 값이 증가 하였다는 선행연구 결과와도 일부 일치한다. ${ }^{35}$

또한, 골격근섬유에서의 전기적 자극은 Type II 근섬유가 수축속도 는 느리고, 수축력은 낮고, 근 지구력은 높은 Type I 근섬유의 특성을 띄게 된다. ${ }^{36,37}$ 근 지구력을 측정하는 각속도 $180 \% / \mathrm{sec}$ 에서 운동 수행 능력이 향상된 것은, 단기간의 러시안 전류자극이 넙다리곧은근의
Type II 근섬유가 Type I으로의 생리학적 특성의 변화에 영향을 미치 기 때문일 것으로 사료되며, 러시안 전류자극과 점진적 저항운동의 근력 및 지구력 향상에 관한 선행연구에서 러시안 전류 자극이 지구 력 향상에 유의한 차이를 보였다는 결과와도 일치한다. 하지만 단일 전기자극에 의한 효과를 명확히 하기에는 주기적인 근육형태 분석 이 이루어지지 못한 제한점이 있다.

각속도 $180 \% \mathrm{sec}$ 에서 굽힘근의 최대 토크 값이 통계적으로 유의한 차이는 없었으나, 러시안 전류 자극 전보다 증가하였고, 각속도 $60 \%$ $\mathrm{sec}$ 에서 굽힘근의 최대 토크가 통계적으로 유의하게 증가한 것은, 빠 른 속도의 무릎관절 폄 움직임 시 무릎관절의 안정성을 위해 뒤넙다 리근은 감속을 위해 신장성 수축을 하게 되는 주동근과 길항근의 안 정성을 높여주는 상관관계에 있기 때문일 것으로 사료된다.35.38 또한 $\mathrm{Bok}$ 등 $^{39}$ 의 단일 외부 모멘트 상황에서 몸통 근육의 동시 수축 형태 에 관한 연구에서 외부 모멘트가 증가함에 따라 길항근의 근력이 크 게 나타난다는 선행 연구결과와도 일치하며 $\mathrm{Cho}$ 와 $\mathrm{Kwon}^{40}$ 의 주동근 과 길항근의 상호 근력 작용에 관한 연구에서 길항근의 근력에는 평 균적으로 증가를 하였으나 통계적으로 유의하지는 않다는 연구결과 와도 일치한다.

본 연구의 제한점은 피험자들의 연계된 동작 반복에 의한 연습효 과를 적절하게 통제하는 데 한계가 있었으며, 러시안 전류 자극 유무 에 따른 등속성 운동수행능력 변화만을 확인한 실험으로, 동시피드 백(concurrent feedback)효과인지 러시안 전류 적용에 의한 혼합효과 인지를 명확히 하기엔 다소 어려움이 있었다.

따라서, 추후 연구에서는 피험자의 연습효과를 통제하기 위한 효 과적인 방법이 필요하며, 러시안 전류 자극에 의한 혼합효과를 명확 히 하기 위해서, 피험자를 러시안 전류 적용그룹, 러시안 전류를 병합 한 등속성 운동그룹, 등속성 운동그룹으로 분류하여 충분한 중재기 간을 거쳐 비교분석이 이루어져야 할 것으로 사료된다.

\section{REFERENCES}

1. Moon CY. A study on the relationships between self-evaluation and job satisfaction of rehabilitation therapist for disability student. A Jou University. Dissertation of Master's Degree. 2011.

2. Rutherford OM, Jones DA, Round JM. Long lasting unilateral muscle wasting and weakness following injury and immobilization. Scand J Rehabil Med. 1990;22:33-7.

3. Fisher NM, Pendergast DR, Gresham GE et al. Muscle rehabilitation: Its effect on muscular and functional performance of patients with knee osteoarthritis. Arch Phys Med Rehabil. 1991;72(6):367-74.

4. Shin HK, Chung BI. The effect of functional strengthening exercise on standing balance in a child with cerebral palsy. Phys Ther Korea. 2001; 8(3):97-105.

5. Rantanen T, Era P, Heikkinen E. Maximal isometric strength and mobil- 
ity among 75-year-old men and women. Age Ageing. 1994;23(2):132-7.

6. Kim YH. Effect of the physical activity promotion program on physical function and quality life in elderly. J Korean Biol Nurs Sci. 2008;10(1): 11-8.

7. Lee HY. Comparison of effects among Tai-Chi exercise, aquatic exercise, and self-help management programs for patients with knee osteoarthritis. Seoul National University. Dissertation of Doctorate Degree. 2005.

8. Maffiuletti NA, Cometti G, Amiridis IG. The effects of electromyostimulation training and basketball practice on muscle strength and jumping ability. Int J Sports Med. 2000;21(6):437-43.

9. Rebai H, Barra V, Laborde A et al. Effects of electrical stimulation frequencies in thigh muscle after knee surgery. J Sports Med. 2002;23(1):315.

10. Kots YM. Electrostimulation Canadian-Soviet exchange symposium on electrostimulation of skeletal muscles. Concordia University, Montreal, Quebec, Canada, 1977;6-15.

11. Selkowitz DM. Improvement in isometric strength of the quadriceps femoris muscle after training with electrical stimulation. Phys Ther. 1985;70:416-22.

12. Robertson VJ, Ward A, Low J et al. Electrotherapy Explained: Principle and Practice. 4th ed. Oxford, Butterworth Heinemann, 2006.

13. Lee SC, Chae JR, Kim HJ. The effect of neromuscular electrical stimulation and isometric exercise on the strength of the quadriceps femoris muscle. J Korean Soc Living Environ Sys. 2009;16(3):239-45.

14. Jung BO, Bang HS. Effect of russian current stimulation on muscular performance and muscle activity of quadriceps femoris muscle of convalescent patient after leg fracture. Journal of Digital Convergence. 2014;12(7):365-70.

15. Park JS, Lee HY. The effect of peak torque, power and muscle endurance in ankles by 12 weeks isokinetic training. Exercise Science. 1998;7(1):8192.

16. Han SW, Baek YO, Kim SS. The effect of funtional performance and muscular strength in the quadriceps and hamstring between isotonic and isokinetic exercise in closed kinetic chan type. JCD. 2010;12(1):16170.

17. Bang HS, Kim JS. The effects of angular velocity on muscle strength of biceps brachii. J Korean soc phys med. 2009;4(3):157-64.

18. Jung HY, Choi SW. The effect of isokinetic training on isokinetic muscle function and bone mineral density of a lumbago patient. The Korea Journal of Sports Science. 2009;18(3):1085-96.

19. Montgomery LC, Douglass LW, Deuster PA. Reliability of isokinetic muscle endurance test. J Orthop Sports Phys Ther. 1989;10(8):315-22.

20. Choi HK. A comparative analysis of isokinetic muscular strength between female volleyball and soccer players. Hanyang University. Dissertation of Master's Degree. 1998.

21. Han NM, Kim HD, Hwang JS. The Utility of Measuring Paravertebral Muscle Function with 3D-NEWTON. J Kor Phys Ther. 2013;25(1):1622.

22. Jeong HY, Choi JD. The Effects of Vestibular Sensory Stimulation Train- ing on Balance and Gait in the Patients with Stroke. J Kor Phys Ther. 2014;26(5):365-71.

23. Park BJ, Kim JH. The Effects of Strengthening Exercise of Hip Abductors on Muscle Strength and Ambulation in Patient with ACL Reconstruction. J Kor Phys Ther. 2014;26(5):296-301.

24. Jang DJ, Kang SJ, Bae TS et al. Development of magneto-rheological fluid control system for isotonic lumbar exercise system. J Inst Contr Robot Syst. 2009;38:586-90.

25. Kim KS, Park JK, Kim DS. Status and characteristics of occurrence of work-related musculoskeletal disorders. J Ergon Soc Korea. 2010;29(4): 405-22.

26. Sole G, Hamrén J, Milosavljevic S et al. Test-retest reliability of isokinetic knee extension and flexion. Arch Phys Med Rehabil. 2007;88(5):626-31.

27. Kim GW, Kim JS. Analysis of Surface EMG Power Spectrum and Muscle Fatigue Depending on the Variable of Neuromuscular Electrical Stimulation. J Kor Phys Ther. 2014;26(5):280-9.

28. Perrin DH. Isokinetic exercise and assessment. Human Kinetics Publisher, 1993.

29. Jang MJ, Lee TH. A stude on the deaf s knee isokinetic muscular strength. The Journal of Physical Education. 1997;25:361-80.

30. Davies GJ. A compendium of isokinetics in clinical usage. 2nd education. Labrary of congress cataloguing in publication, 1984:265-9.

31. Hill DK. Tension due to interaction between the sliding filaments in resting striated muscle. J Physiol. 1968;199(3):637-84.

32. Won KH, Kim C, Kim CK. Effects of electromyostimulation and weight training on muscle morphology and function. The Korean Journal of Education. 2001;40(1):490-8.

33. Thorstensson A, Grimby G, Karlsson J. Force-velocity relations and fiber composition in human knee extensor muscles. J Appl Physiol. 1976; 40(1):12-6.

34. Ivy JL, Withers RT, Brose G et al. Isokinetic contractile properties of the quadriceps with relation to fiber type. Eur J Appl Physiol Occup Physiol. 1981;47(3):247-55.

35. Lim WG, Lim SK. Conventional and functional ratios for isokinetic hamstring: quadriceps muscle strength. Journal of Sport and Leisure.2009;38:845-54.

36. Hudlicka O, Brown M, Cotter M et al. The effect of long-term stimulation of fast muscles on their blood flow, metabolism and ability to withstand fatigue. Pflugers Arch. 1977;369(2):141-9.

37. Lee JH. Electrotherapy. Seoul, Daehakseorim, 1995:148-51.

38. Kang KS, Jang JS, Moon JH et al. The role of the hamstrings as antagonist of quadriceps in maintaining knee joint stability. J of Korean Orthop Assoc. 1991;26(3):945-9.

39. Bok IG, Song YW, Chung MK. Trunk muscle coactivation level in single external movement conditions. J Ergon Soc Korea. 2002;11:283-6.

40. Cho MS, Kwon TW. A study on inter relationship of strength between agonistic muscle and antagonistic muscle. The Korea Journal of Sports Science. 2012;21(5):1213-22. 